\title{
Outpatient treatment and early discharge of symptomatic pulmonary embolism: a systematic review
}

\author{
A. Squizzato, M. Galli, F. Dentali and W. Ageno
}

ABSTRACT: The published literature regarding the safety of outpatient treatment of symptomatic pulmonary embolism (PE) was systematically summarised.

A literature search was performed using the PubMed and EMBASE databases. Studies in which patients had symptomatic PE and the antithrombotic treatment was administered completely at home or the patients were discharged early were selected. A scoring system was used to divide studies into three quality categories. Short- and long-term outcomes were extracted: all-cause mortality, death from PE or from major haemorrhage, recurrent venous thromboembolism, and major bleeding.

Eleven observational studies were included. No randomised controlled studies were identified. No study fulfilled the criteria for high quality. A total of 928 patients with symptomatic PE were treated completely as outpatients or discharged early; haemodynamic instability and hypoxia were the main exclusion criteria. No patient died during the first 7 days of antithrombotic treatment.

Outpatient treatment of symptomatic PE is not based on high-quality evidence. Although the published data suggest that certain subgroups of haemodynamically and respiratorily stable patients may be safely treated at home when a well-defined management programme is applied, further studies are warranted for a short-term prognostic risk stratification of this PE subgroup.

KEYWORDS: Early discharge, home treatment, low-molecular-weight heparin, outpatient treatment, pulmonary embolism

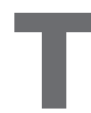

he selection of patients with symptomatic pulmonary embolism (PE) who may be safely treated on an outpatient basis remains a matter of debate. The latest edition of the American College of Chest Physicians guidelines discusses home treatment of PE, but no recommendations have been stated [1]. The task force of the European Society of Cardiology hypothesises, but does not clearly recommend, early discharge or home treatment for PE with a low risk of death in the recently published guidelines [2]. The guidelines of the American College of Physicians and the American Academy of Family Physicians state that outpatient treatment of deep venous thrombosis (DVT), and possibly of PE, with low-molecularweight heparin (LMWH) is safe and cost-effective [3]. The British Thoracic Society has recommended that the current arrangements for the outpatient management of DVT should be extended to include stable patients with PE [4]. However, there are no widely accepted criteria for defining PE patients who can be deemed eligible for outpatient treatment.

The purpose of the present review was to systematically summarise the published literature regarding the safety of outpatient treatment of symptomatic PE, in order to provide an evidence-based approach for treating physicians and future research projects.

\section{METHODS}

\section{Data sources and searches}

A computer-assisted search of the PubMed and EMBASE electronic databases was performed up to January 2008 in order to identify published studies on the outpatient treatment of symptomatic PE.
AFFILIATIONS

Dept of Clinical Medicine, University of Insubria, Varese, Italy.

CORRESPONDENCE

A. Squizzato

Medicina 1 - Ospedale di Circolo, viale Borri 57 21100 Varese Italy

Fax: 390332278691

E-mail: alexsquizzo@libero.it

Received:

August 292008

Accepted after revision:

November 252008

SUPPORT STATEMENT

This study was originally presented as a poster at the 20th International Congress on Thrombosis, Athens,

Greece, June 25-28, 2008.

STATEMENT OF INTEREST

None declared. 
The following search terms (text words and MeSH or EMTREE terms, respectively) were used for the PubMed search: "pulmonary embolism", "outpatients", "ambulatory care" and "home therapy"; and the EMBASE search: "pulmonary embolism", "lung embolism", "outpatient", "ambulatory care" and "home therapy".

No language restrictions were initially applied to the search strategy. The reference lists of all studies included in the present systematic review were screened for potential additional eligible studies. A letter and/or an e-mail was sent to the corresponding author if the full manuscript was unavailable.

\section{Study selection}

Two investigators (M. Galli and A. Squizzato) concomitantly performed the study selection. The main inclusion criterion was that the patients had symptomatic PE and that the initial antithrombotic treatment was administered partially (early discharge) or totally at home. Only studies clearly stating the outpatient setting of the initial treatment were included, and studies in which this criterion was not evident were excluded. Randomised controlled studies, observational studies and case reports were considered. Reviews, editorials and non-human studies were excluded. The two investigators concomitantly reviewed titles and/or abstracts from the initial search in order to determine whether or not the inclusion criteria were satisfied. Studies not clearly eligible after reading the title and/or abstract were evaluated for selection after retrieving the full text. Disagreement between reviewers was resolved through discussion. In the case of persisting disagreement, the opinion of a third reviewer (W. Ageno) was requested. Where multiple articles had been published for a single study, it was decided to use the latest publication and to supplement it, if necessary, with data from the earlier publications.

\section{Data extraction and quality assessment}

For randomised controlled trials (RCTs), quality assessment was planned by means of a validated scale [5]. For observational cohort studies, although the use of quality scoring systems or quality scales is controversial [6], study quality was assessed using the following items: type of study (prospective or retrospective); patient selection (consecutive patients without potential bias of selection); control group; short- and long-term ( $\geqslant 3$ months) follow-up with data; and number of patients lost to follow up $(<5 \%, 5-20 \%$ or $>20 \%)$.

For each fulfilled item, one point was given. For the last item, one point was given for $<5 \%$ of patients lost to follow-up, and half a point for $5-20 \%$. A scoring system was adapted to identify three quality categories as follows: a total of five points defined high-quality studies; 4 points defined medium-quality studies; and $\leqslant 3$ points defined low-quality studies.

The total number of cases was also ascertained as an additional quality item. The quality assessment form is available upon request from the present authors.

No attempts were made to mask for authorship, journal name or institution.

One reviewer (M. Galli) completed the data extraction form. A second reviewer (A. Squizzato) checked the extracted data. The following characteristics were collected: 1) total number of patients; 2) mean age; 3) sex; 4) exclusion criteria for outpatient treatment; 5) definition of outpatient treatment management; 6) antithrombotic therapy; 7) short-term (first week or until LMWH was administered) and long-term ( $\geqslant 3$ months) outcomes: all cause mortality, death from PE or from major haemorrhage, recurrent venous thromboembolism (VTE), and major bleeding; and 8) quality assessment data.

\section{Data synthesis and analysis}

Data for qualitative variables are presented as incidence rates (i.e. number and percentage). The data of continuous variables are summarised using measures of central tendency (i.e. mean and median) and dispersion (i.e. SD and range).

\section{TABLE 1 Quality assessment}

\begin{tabular}{|c|c|c|c|c|c|c|c|c|}
\hline \multirow{2}{*}{$\begin{array}{l}\text { First author } \\
\text { [Ref.] }\end{array}$} & \multirow[t]{2}{*}{ Year } & \multirow[t]{2}{*}{ Design } & \multirow{2}{*}{$\begin{array}{c}\text { Consecutive } \\
\text { patients }\end{array}$} & \multirow{2}{*}{$\begin{array}{c}\text { Control } \\
\text { group }\end{array}$} & \multirow{2}{*}{$\begin{array}{c}\text { PE patients } \\
\mathbf{n}\end{array}$} & \multicolumn{2}{|c|}{ Follow-up } & \multirow{2}{*}{$\begin{array}{c}\text { Quality } \\
\text { score }\end{array}$} \\
\hline & & & & & & $\begin{array}{l}\text { Duration } \\
\text { months }\end{array}$ & $\begin{array}{c}\text { Lost patients } \\
\text { n (\%) }\end{array}$ & \\
\hline Kovacs [27] & 2000 & Prospective cohort & Yes & No & 108 & 3 & 0 & 3 \\
\hline BEER [19] & 2003 & Prospective cohort & No & Yes & 43 & 3 & 0 & 3 \\
\hline BULLER [20] & 2003 & Prospective inception cohort & No & No & 158 & $1-2$ weeks & 0 & 2 \\
\hline LIM [29] & 2003 & Retrospective case note review & No & No & 70 & 6 & 0 & 2 \\
\hline SiRAgusa [35] & 2005 & Prospective cohort & Yes & Yes & 36 & 6 & 0 & 4 \\
\hline WeLLs [37] & 2005 & Prospective inception cohort & No & No & 90 & 3 & 0 & 2 \\
\hline ONG [32] & 2005 & Retrospective database- and record-based review & Yes & No & 130 & 3 & 1 & 3 \\
\hline AgEno [9] & 2005 & Retrospective record-based review & No & Yes & 23 & 3 & 0 & 2 \\
\hline OLsson [31] & 2006 & Prospective cohort & No & No & 102 & 13 & $2(2)$ & 3 \\
\hline DAVIES [22] & 2007 & Prospective cohort & No & No & 157 & 3 & $1(0.6)$ & 3 \\
\hline LUI [30] & 2007 & Retrospective record-based review & Yes & No & 21 & 1-2 weeks & 0 & 2 \\
\hline
\end{tabular}




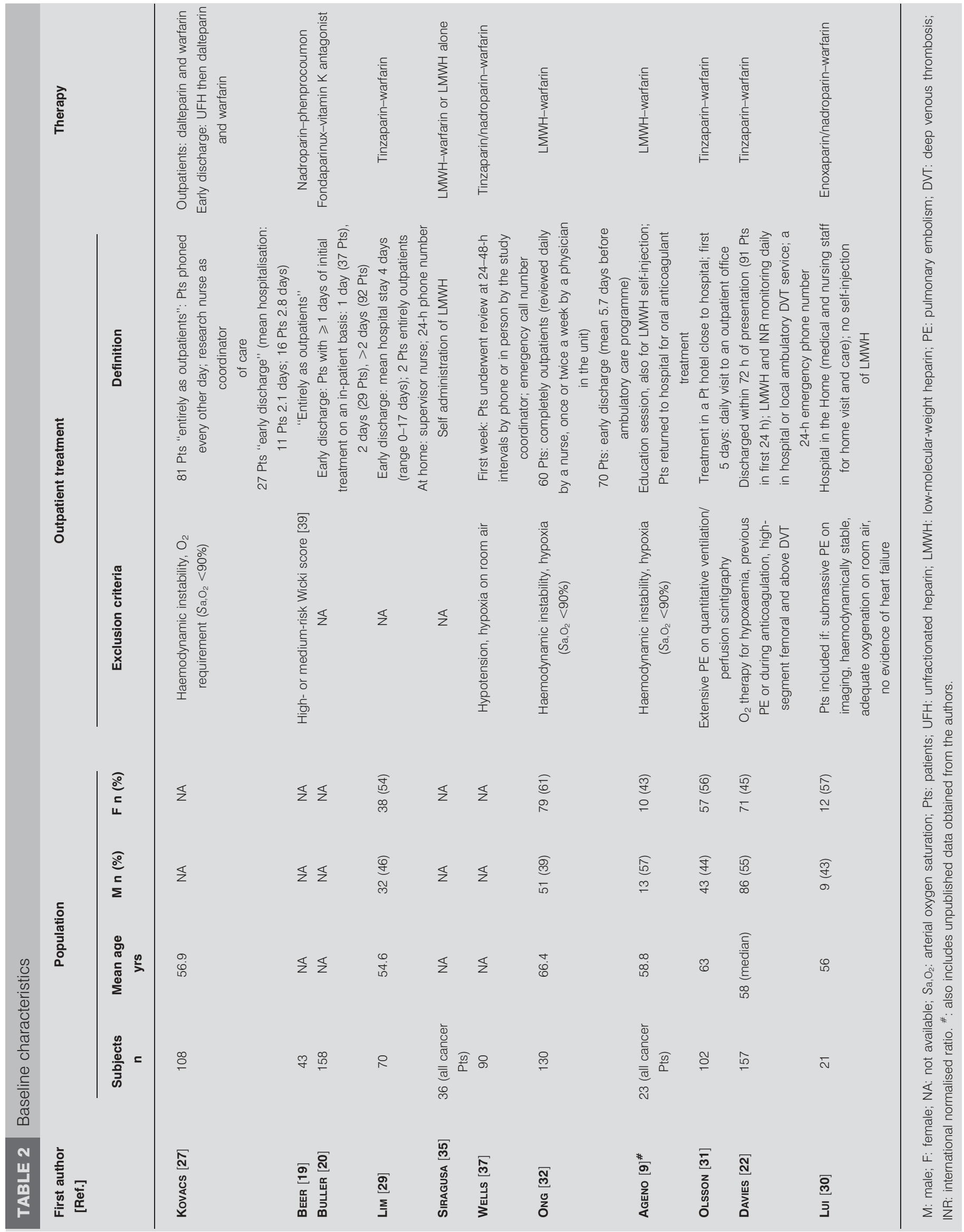


TABLE 3 Observational studies without outcome data

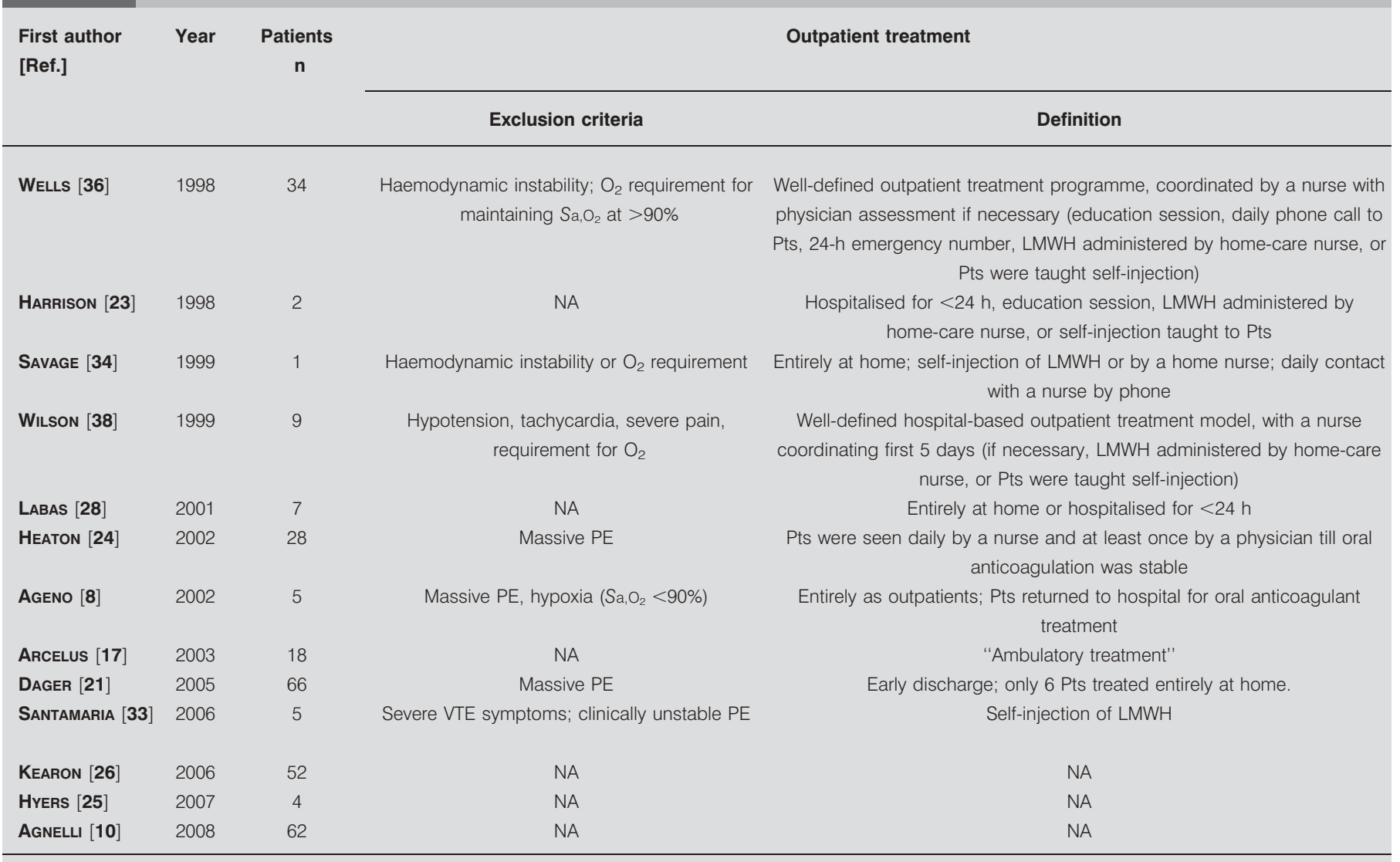

$\mathrm{Sa}_{2} \mathrm{O}_{2}$ : arterial oxygen saturation; Pts: patients; LMWH: low-molecular-weight heparin; NA: not available; PE: pulmonary embolism; VTE: venous thromboembolism.

\section{RESULTS}

Using the initial computed-assisted search strategy, 1,060 references were identified. Of these, 83 were considered potentially eligible based on the title and/or abstract. Full copies of 80 potentially appropriate studies and two abstracts (neither the manuscript nor the abstract could be retrieved for one article) were retrieved [7]. Eight additional articles and one additional abstract (a duplicate publication) were subsequently identified [8-16]. After excluding articles not meeting the prespecified inclusion criteria, a total of 25 studies were considered for the final analysis [8-10, 17-38]. One manuscript was a case report [18]. In 13 articles including both patients with DVT and with PE, it was not possible to obtain separate data on baseline characteristics and outcome events for the PE group alone [8, 10, 17, 21, 23-26, 28, 33, 34, 36, 38]. Therefore, for these studies, it was possible to perform a limited data extraction, but not a quality assessment. For the remaining 11 manuscripts, complete quality assessment and data extraction were performed $[9,19,20,22,27,29-32,35,37]$. No RCTs were identified. Seven observational studies had a prospective cohort design [19, 20, 22, 27, 31, 35, 37]. No study fulfilled the criteria required for high quality (table 1). A single study, which only enrolled patients with cancer, was of medium quality [35].

A total of 928 patients were analysed in these 11 selected observational studies. The mean age was 60.0 yrs. Sex data were available for 501 patients, of whom 224 (46.7\%) were male (table 2). The other 12 studies and the case report enrolled a total of 242 patients (table 3 ).

Besides haemodynamic instability, hypoxia was the most frequent exclusion criterion for outpatient treatment in eight out of 11 studies in which exclusion criteria were reported: the oxygen therapy for an arterial oxygen saturation of $<90 \%$ criterion was certainly used in seven $(87.5 \%)$ studies. Other criteria were: extensive PE on imaging in two $(25 \%)$ studies, heart failure in one $(12.5 \%)$, previous PE or during anticoagulation in one (12.5\%), high-segment femoral and above DVT in one $(12.5 \%)$, and the high or medium risk of the Geneva prognostic score in one $(12.5 \%)$ [39]. Common exclusion criteria for outpatient treatment (concomitant medical condition, likelihood of poor compliance, geographical inaccessibility for follow-up, history or presence of drug addiction and patient's choice) and disease- and drug-related reasons for hospital admission (body weight of $>110 \mathrm{~kg}$, active bleeding or high risk of major bleeding, creatinine clearance of $<30 \mathrm{~mL} \cdot \mathrm{min}^{-1}$, fibrinolytic therapy, thrombocytopenia, contraindication for anticoagulants and pain requiring parenteral narcotics) are not reported in table 2, but were generally used in these studies.

In four out of the eleven studies with available outcome data home therapy was defined by early discharge (1 -5 days) $[21,23,27,32]$. In the remaining seven studies, patients could be entirely treated out of hospital, and, in most cases, a 


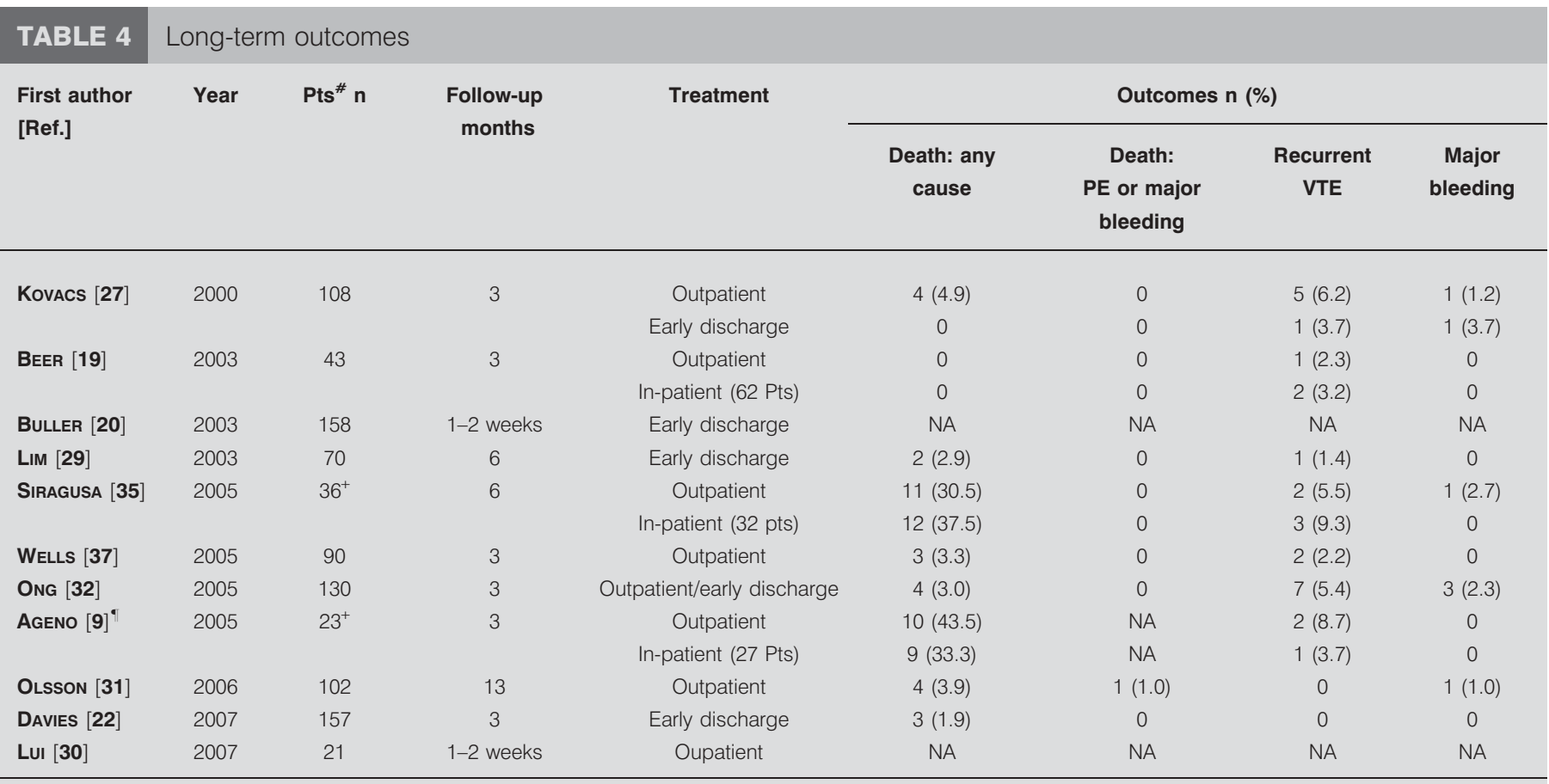

Pts: patients; PE: pulmonary embolism; VTE: venous thromboembolism; NA: not available. " : outpatient or early discharge; ": unpublished data obtained from the authors; ${ }^{+}$: all cancer patients.

description of the outpatient treatment programme is provided. This was usually coordinated by a nurse, included the assessment of a physician, if required, an educational session, a daily phone call to each patient and the availability of a 24-h emergency phone number. Home-care nurses, the patient themself, or a family member administered LMWH. Similar models were described in most of the 12 studies for which outcome data were unavailable (table 3).

Short-term outcomes were available for only six studies: no patient died in the first 7-10 days, seven patients had recurrent VTE and two experienced major bleeding [20, 22, 29-32]. Data on the long-term outcome were available for nine out of the 11 studies $[9,19,22,27,29,31,32,35,37]$. The median duration of follow-up was 3 months (range 2 weeks to 13 months). Mortality rates ranged $0-43.5 \%$ (all in cancer patients) [9]. Data on other outcomes are reported in tables 4 and 5 .

A total of 121 patients, entirely treated in hospital during the initial phase, were included in the available control groups [9, 19, 35]. Long-term outcomes were similar: no patient had died due to PE or major bleeding at 3 months (tables 4 and 5).

\section{DISCUSSION}

The results of the present systematic review of the literature regarding the safety of outpatient treatment of symptomatic PE suggest that certain subgroups of haemodynamically and respiratorily stable patients may be safely treated completely or partially (early discharge) at home using a well-defined management programme. However, the safety of home therapy is not based on high-quality evidence, and, therefore, further studies are warranted for a better short-term prognostic risk stratification of this PE subgroup.
Clinical trials have established that LMWH is at least as safe and effective as unfractionated heparin in the treatment of VTE $[40,41]$. Moreover, two major RCTs have also established that the outpatient administration of LMWH is as safe as unfractionated heparin administered in hospital for the treatment of DVT [42-44]. For these reasons, outpatient treatment of patients with DVT, with or without asymptomatic PE, has become common practice worldwide. Although DVT and PE are two manifestations of the same disease process, PE is still mainly treated in hospital. High-risk PE has a risk of early death (understood as in-hospital or 30-day mortality) of $>15 \%$, and hospital admission is, indeed, mandatory [2]. Conversely, a subgroup of patients with nonhigh-risk PE, defined in the recent guidelines of the European Society of Cardiology as "low risk PE", has a mortality rate of $<1 \%$ and hospital admission may not be necessary for all patients [2].

Several studies have been performed to demonstrate the safety of outpatient treatment or early discharge of symptomatic PE and have been systematically reviewed in the present manuscript. Based on the quality of the available evidence, it should be concluded that information regarding the safety of outpatient treatment of PE is still inadequate. No RCTs have ever been performed to compare in-patient and outpatient management of PE, and the majority of observational studies are of low quality. A multicentric European RCT, in which patients were discharged from the emergency department within $24 \mathrm{~h}$ after randomisation or admitted to the hospital and discharged based on the decision of the managing physician, is recruiting PE patients at low risk according to the pulmonary embolism severity index (PESI) [45]. The PESI is a clinical prediction rule based on 11 variables developed to stratify patients with PE 


\section{TABLE 5 Short-term outcomes}

\begin{tabular}{|c|c|c|c|c|c|c|}
\hline First author [Ref.] & Year & Treatment & $\begin{array}{c}\text { Any cause of death } \\
n(\%)\end{array}$ & $\begin{array}{l}\text { Death due to PE or major } \\
\text { bleeding } n(\%)\end{array}$ & $\begin{array}{c}\text { Recurrent VTE } \\
\text { n (\%) }\end{array}$ & $\begin{array}{c}\text { Major bleeding } \\
n(\%)\end{array}$ \\
\hline BuLleR [20] & 2003 & Early discharge & 0 & 0 & $5(3.2)$ & 0 \\
\hline LIM [29] & 2003 & Early discharge & 0 & 0 & 0 & 0 \\
\hline DAVIES [22] & 2007 & Early discharge & 0 & 0 & 0 & 0 \\
\hline LUI [30] & 2007 & Outpatient & 0 & 0 & 0 & 0 \\
\hline
\end{tabular}

PE: pulmonary embolism; VTE: venous thromboembolism.

into five risk categories of 90-day mortality: patients in the two lowest risk groups have a mortality rate of $<2 \%$ and are currently included in this study [45, 46]. Until new data are available, however, after taking into account all methodological drawbacks, the published data on short- and long-term outcomes consistently suggest that home therapy of PE may be safe and appears feasible. No deaths have been reported in the first 7-10 days, and data on recurrent VTE and on major bleeding are similar to those reported in control groups, where available, and in the literature. A well-defined outpatient management programme appears to be a necessary condition of provision of safe treatment.

A number of limitations of the present systematic review may affect the validity of the present findings. First, no attempt was made to contact authors for missing data. However, given the low quality of the published studies, additional data would probably not have changed the present conclusions. Only a RCT may substantially improve study quality. Secondly, some sources of bias, such as confounding measurement or outcome measurement, have not been systematically assessed. However, no quality scoring systems or quality scales are widely accepted, and, even if the choice of quality criteria can be criticised, assessing new criteria would not improve study quality [6]. Thirdly, stratification of patients based on new prognostic markers, such as troponin, brain natriuretic peptide and echocardiographic parameters, is not available, and it is not yet possible to identify subgroups of patients who may be safely treated at home [47]. Only in one study were patients considered eligible for the outpatient treatment based on a well-defined prognostic score, the Geneva score $[19,39]$. However, no consensus exists regarding which single marker or score is the most reliable and thus the best indicator of prognosis [47]. Future studies could explore the role of prognostic markers in improving the selection process of PE patients eligible for outpatient management [48]. Fourthly, in two studies, the definition of early discharge was at least debatable: LIM et al. [29] had a mean hospital stay of 4 days, with a wide range of 0-17 days, and ONG et al. [32] enrolled 70 patients who were discharged after a mean of 5.7 days. Given that the authors consider these periods as early discharge, this reinforces the need for welldefined and accepted criteria for safe home treatment. Fifthly, several patients with PE had cancer, and, in particular, two studies included in the present analysis enrolled only cancer patients $[9,35]$. In these studies, mortality rates at 3 months were very high (30.5-40.5\%). However, the high mortality rates were mainly due to the underlying disease and not related to recurrent VTE or treatment-related bleeding. Moreover, given the burden of medical treatments and frequency of hospital admissions, the present authors believe that home therapy of PE may certainly improve the quality of life of these patients.

Finally, a review has recently been published on the same topic [49]. Even if the conclusions are similar, there are some relevant underlying differences. First, a quality assessment was not attempted. The use of quality scoring systems or quality scales for observational cohort studies is still a matter of discussion, but quality assessment cannot be omitted in a systematic review because it is extremely relevant and useful for the reader $[6,50]$. Secondly, the present inclusion and exclusion criteria were less strict. Given the low quality of published studies on this topic, inclusion of more studies did not change the quality of the presented data. Moreover, this permitted data to be shown on short-term outcomes and the design of studies in which the authors declared treating patients at home to be summarised without reporting separate outcomes for PE (table 3). Thirdly, and most relevantly, the definition of outpatient treatment was reported for each included study. It is compelling to specify that a dedicated well-organised 24-h outpatient programme should be provided to each patient treated at home. In most published studies, it was usually coordinated by a nurse, and included: the assessment of a physician, an educational session, a daily phone call to each patient, the availability of a 24-h emergency phone number, and a home-care nurse for administration of LMWH where necessary. A correct prognostic stratification is the first step, but a dedicated outpatient service is necessary.

In summary, it is concluded that the outpatient management of symptomatic PE is currently not based on high-quality evidence. Although the available data suggest that certain subgroups of stable patients with normal blood pressure and no requirement for oxygen therapy may be safely treated at home when a well-defined management programme is applied, further studies are warranted for a better short-term prognostic risk stratification of this PE subgroup. 


\section{REFERENCES}

1 Kearon C, Kahn SR, Agnelli G, Goldhaber S, Raskob GE, Comerota AJ. Antithrombotic therapy for venous thromboembolic disease: American College of Chest Physicians Evidence-Based Clinical Guidelines ( ${ }^{\text {th }}$ Edition). Chest 2008; 133: 454S-545S.

2 Torbicki A, Perrier A, Konstantinides S, et al. Guidelines on the diagnosis and management of acute pulmonary embolism: the Task Force for the Diagnosis and Management of Acute Pulmonary Embolism of the European Society of Cardiology (ESC). Eur Heart J 2008; 29: 2276-2315.

3 Snow V, Qaseem A, Barry P, et al. Management of venous thromboembolism: a clinical practice guideline from the American College of Physicians and the American Academy of Family Physicians. Ann Intern Med 2007; 146: 204-210.

4 British Thoracic Society Standards of Care Committee Pulmonary Embolism Guideline Development Group. British Thoracic Society guidelines for the management of suspected acute pulmonary embolism. Thorax 2003; 58: 470-483.

5 Jadad AR. Assessing the quality of reports of randomized clinical trials: is blinding necessary? Control Clin Trials 1996; 17: 1-12.

6 Stroup DF, Berlin JA, Morton SC, et al. Meta-analysis of observational studies in epidemiology. A proposal for reporting. JAMA 2007; 283: 2008-2012.

7 Stammler F, Bauersachs RM, Niedermeyer J. Outpatient treatment of pulmonary embolism with low molecular weight heparin (multiple letters). Dtsch Med Wochenschr 2000; 125: 711-712.

8 Ageno W, Steidl L, Marchesi C, et al. Selecting patients for home treatment of deep vein thrombosis: the problem of cancer. Haematologica 2002; 87: 286-291.

9 Ageno W, Grimwood R, Limbiati S, Dentali F, Steidl L, Wells PS. Home-treatment of deep vein thrombosis in patients with cancer. Haematologica 2005; 90: 220-224.

10 Agnelli G, Verso M, Ageno W, et al. The MASTER registry on venous thromboembolism: description of the study cohort. Thromb Res 2008; 121: 605-610.

11 Hull RD, Pineo GF, Brant RF, et al. Self-managed long-term low-molecular-weight heparin therapy: the balance of benefits and harms. Am J Med 2007; 120: 72-82.

12 Lee AY, Levine MN, Baker RI, et al. Low-molecular-weight heparin versus a coumarin for the prevention of recurrent venous thromboembolism in patients with cancer. $N$ Engl J Med 2003; 349: 146-153.

13 Rhodes S, Bond S, Green S, et al. Outpatient management of pulmonary embolism: results from the national multicenter PE study. Blood 2005; 106: 911.

14 Simonneau G, Sors H, Cherbonnier B, et al. A comparison of low-molecular weight heparin with unfractioned heparin for acute pulmonary embolism. N Engl J Med 1997; 337: 663-669.

15 Tanvetyanon T, Cohn JB. Eligibility for outpatient treatment with low-molecular-weight heparin in venous thromboembolism. Arch Intern Med 2000; 160: 869-870.

16 The van Gogh Investigators, Idraparinux versus standard therapy for venous thromboembolic disease. $N$ Engl J Med 2007; 357: 1094-1104.

17 Arcelus JI, Caprini JA, Monreal M, Suárez C, GonzálezFajardo J. The management and outcome of acute venous thromboembolism: A prospective registry including 4011 patients. J Vasc Surg 2003; 38: 916-922.
18 Bauersachs RM, Lindhoff-Last E, Ehrly AM. Out-patient treatment of acute pulmonary embolism and fresh proximal deep vein thrombosis with low molecular weight heparin. Dtsch Med Wochenschr 1999; 124: 1485-1488.

19 Beer JH, Burger M, Gretener S, Bernard-Bagattini S, Bounameaux H. Outpatient treatment of pulmonary embolism is feasible and safe in a substantial proportion of patients. J Thromb Haemost 2003; 1: 186-187.

20 Buller HR, Davidson BL, Decousus H, et al. Subcutaneous fondaparinux versus intravenous unfractionated heparin in the initial treatment of pulmonary embolism. New Engl J Med 2003; 349: 1695-1702.

21 Dager WE, King JH, Branch JM, et al. Tinzaparin in outpatients with pulmonary embolism or deep vein thrombosis. Ann Pharmacother 2005; 39: 1182-1187.

22 Davies CW, Wimperis J, Green ES, et al. Early discharge of patients with pulmonary embolism: a two-phase observational study. Eur Respir J 2007; 30: 708-714.

23 Harrison L, McGinnis J, Crowther M, Ginsberg J, Hirsh J. Assessment of outpatient treatment of deep-vein thrombosis with low- molecular-weight heparin. Arch Intern Med 1998; 158: 2001-2003.

24 Heaton D, Han DY, Inder A. Outpatient treatment of community acquired venous thromboembolism - the Christchurch experience. N Z Med J 2002; 115: U105.

25 Hyers TM, Spyropoulos AC. Community-based treatment of venous thromboembolism with a low-molecular-weight heparin and warfarin. J Thromb Thrombolysis 2007; 24: 225-232.

26 Kearon C, Ginsberg JS, Julian JA, et al. Comparison of fixed-dose weight-adjusted unfractioned heparin and lowmolecular-weight heparin for acute treatment of venous thromboembolism. JAMA 2006; 296: 935-942.

27 Kovacs MJ, Anderson D, Morrow B, Gray L, Touchie D, Wells PS. Outpatient treatment of pulmonary embolism with dalteparin. Thromb Haemost 2000; 83: 209-211.

28 Labas P, Ohradka B, Cambal M. Could deep vein thrombosis be safely treated at home? Bratisl Lek Listy 2001; 102: 458-461.

29 Lim AY, Parr DG, Stableforth DE, Fellows M, Fontaine R, Fegan CD. Early discharge and home supervision of patients with pulmonary embolism treated with lowmolecular weight heparin. Eur J Intern Med 2003; 14: 89-93.

30 Lui B, Tran A, Montalto M. Treatment of patients with pulmonary embolism entirely in Hospital in the Home. Aust Fam Physician 2007; 36: 381-384.

31 Olsson CG, Bitzen U, Olsson B, et al. Outpatient tinzaparin therapy in pulmonary embolism quantified with ventilation/perfusion scintigraphy. Med Sci Monit 2006; 12: I9-I13.

32 Ong BS, Karr MA, Chan DKY, Frankel A, Shen Q. Management of pulmonary embolism in the home. Med J Aust 2005; 183: 239-242.

33 Santamaría A, Juárez S, Reche A, et al. Low-molecular-weight herapin, bemiparin, in the outpatient treatment and secondary prophylaxis of venous thromboembolism in standard clinical practice: The ESFERA study. Int J Clin Pract 2006; 60: 518-525.

34 Savage KJ, Wells PS, Schulz V, et al. Outpatient use of low molecular weight heparin (dalteparin) for the treatment of deep vein thrombosis of the upper extremity. Thromb Haemost 1999; 82: 1008-1010. 
35 Siragusa S, Arcara C, Malato A, et al. Home therapy for deep vein thrombosis and pulmonary embolism in cancer patients. Ann Oncol 2005; 16: iv136-iv139.

36 Wells PS, Kovacs MJ, Bormanis J, et al. Expanding eligibility for outpatient treatment of deep venous thrombosis and pulmonary embolism with low-molecularweight heparin: a comparison of patient self-injection with homecare injection. Arch Intern Med 1998; 158: 1809-1812.

37 Wells PS, Anderson DR, Rodger MA, et al. A randomized trial comparing 2 low-molecular-weight heparins for the outpatient treatment of deep vein thrombosis and pulmonary embolism. Arch Intern Med 2005; 165: 733-738.

38 Wilson SJA, Gray L, Anderson DR. Outpatient treatment of deep vein thrombosis and pulmonary embolism: a hospitalbased program. Can J Hosp Pharm 1999; 52: 282-288.

39 Wicki J, Perrier A, Perneger TV, Bounameaux H, Junod AF. Predicting adverse outcome in patients with acute pulmonary embolism: a risk score. Thromb Haemost 2000; 84: 548-552.

40 Quinlan DJ, McQuillan A, Eikelboom JW. Low-molecularweight heparin compared with intravenous unfractioned heparin for treatment of pulmonary embolism: a metaanalysis of randomized, controlled trials. Ann Intern Med 2004; 140: 175-183.

41 van Dongen CJ, ven den Belt AG, Prins $M H$, Lensing AW. Fixed dose subcutaneous low-molecular weight heparins versus adjusted dose unfractioned heparin for venous thromboembolism. Cochrane Database Syst Rev 2004; 4: CD001100.

42 Koopman MM, Prandoni P, Piovella F, et al. Treatment of venous thrombosis with intravenous unfractionated heparin administered in the hospital as compared with subcutaneous low-molecular-weight heparin administered at home. New Engl J Med 1996; 334: 682-687.

43 Levine M, Gent M, Hirsh J, et al. A comparison of lowmolecular-weight heparin administered primarily at home with unfractioned heparin administered in the hospital for proximal deep-vein thrombosis. N Engl J Med 1996; 334: 677-681.

44 Othieno R, Abu Affan M, Okpo E. Home versus in-patient treatment for deep vein thrombosis. Cochrane Database Syst Rev 2007; 3: CD003076.

45 ClinicalTrials, Safety Study of Outpatient Treatment for Pulmonary Embolism (OTPE). www.clinicaltrial.gov/ct2/ show/NCT00425542 Date last updated: January 2009. Date last accessed: 4 March 2009.

46 Aujesky D, Roy PM, Le Manach CP, et al. Validation of a model to predict adverse outcomes in patients with pulmonary embolism. Eur Heart J 2006; 27: 476-481.

47 Becattini C, Agnelli G. Acute pulmonary embolism: risk stratification in the emergency department. Intern Emerg Med 2007; 2: 119-129.

48 Jimenez D, Yusen RD, Otero R, et al. Prognostic models for selecting patients with acute pulmonary embolism for initial outpatient therapy. Chest 2007; 132: 24-30.

49 Janjua M, Badshah A, Matta F, Danescu LG, Yaekoub AY, Stein PD. Treatment of acute pulmonary embolism as outpatients or following early discharge. A systematic review. Thromb Haemost 2008; 100: 756-761.

50 Higgins JPT, Green S, eds, Cochrane Handbook for Systematic Reviews of Interventions. Version 5.0.1. The Cochrane Collaboration, 2008. www.cochrane-handbook.org Date last updated: September 2008. Date last accessed: 4 March 2009. 